\title{
Immobilization of pyrene-adorned N-heterocyclic carbene complexes of rhodium (I) on reduced graphene oxide and study of catalytic activity
}

\author{
Sheila Ruiz-Botella, ${ }^{[b]}$ and Eduardo Peris ${ }^{*[a]}$
}

\begin{abstract}
Two pyrene-tagged $\mathrm{N}$-heterocyclic carbene complexes of rhodium (I) were obtained and characterized. The two complexes were supported onto reduced-graphene oxide (rGO), generating two new materials in which the molecular complexes are immobilized by $\pi-\pi$-stacking interactions onto the surface of the solid. The catalytic activity of both complexes and solid hybrid materials were studied in the 1,4-addition of phenylboronic acid to cyclohex-2-one, and in the hydrosilylation of terminal alkynes. The studies showed that for both reactions the dimetallic complex displayed better catalytic performances than the monometallic one. This accounted for both, the reactions carried out in homogeneous conditions and for the reactions carried out with the solid. In the case of the addition of phenyboronic acid to cyclohexanone, the solid containing the dimetallic catalyst could be effectively recycled up to five times, with negligible loss of activity, while the monometallic catalyst rapidly got inactive activity. In the hydrosilylation of terminal alkynes, the selectivity towards the $\beta(Z)$-vinylsilane was improved when the immobilized dimetallic catalyst was used, although the catalyst started to loss activity after the second run.
\end{abstract}

\section{Introduction}

While homogeneous catalysts usually show the advantages of high activity and high selectivity, their wide application in the industrial large-scale production of materials remains limited due to the difficulties encountered when trying to separate the reaction products from the catalyst and from the reaction solvent. ${ }^{[1]} \mathrm{A}$ strategy to combine the best attributes from homogenous (high activity and selectivity) and heterogeneous (catalyst recovery and recyclability) catalysts is to use supported metal-based catalysts. The most widely used strategy for catalyst immobilization is the formation of a covalent bond between the solid and one of the ligands of the homogeneous catalyst. This requires that the catalyst has an additional functionalization, but this often raises the catalyst preparation cost and may modify its catalytic properties. Non-covalent methods for catalyst immobilization

[a] Institute of Advanced Materials (INAM)

Universitat Jaume I

Avda. Sos Baynat. E-12071-Castellón. Spain

Fax: (+) 34964387522

E-mail: eperis@uji.es

Supporting information for this article is given via a link at the end of the document. have gained interest because they offer a much simpler approach to catalyst immobilization, $\left.{ }^{[1]}\right]$ although they may suffer from the disadvantage that the link between the catalyst and the solid is sometimes not too strong. Carbon surfaces are interesting materials for catalyst immobilization, because they offer excellent thermal and mechanical stability, high surface area and a rich surface chemistry. [2] Due to the inherent capability of pyrene to afford $\pi$-stacking interactions with graphitic surfaces, ${ }^{[3]}$ pyrenetagged metal complexes have been efficiently supported onto graphitized solids, ${ }^{[4]}$ and some have also been used in catalysis proving interesting recyclability properties. ${ }^{[5]}$

Due to their easy accessibility and high tunability, N-heterocyclic carbenes (NHCs) have been found to be excellent ligands for catalyst immobilization. ${ }^{[6]}$ We recently contributed to the field, by preparing a series of pyrene-tagged $\mathrm{NHC}$-based catalysts, which were supported onto reduced graphene oxide (rGO), and afforded excellent recyclability in reactions such as the hydrodefluorination of aromatic fluorocarbenes, ${ }^{[7]}$ hydrogenation of alkenes and alcohol oxidation, ${ }^{[8]}$ and in the $\beta$-alkylation of secondary alcohols with primary alcohols. ${ }^{[9]}$ In most of these processes, we found that the presence of the pyrene-tags bound to the NHC ligands, allowed the effective non-covalent immobilization of the homogeneous catalyst onto the graphene derivative surface, but also induced significant modifications on the properties of the homogeneous catalyst, which we related to $\pi-\pi$-stacking interactions established between the aromatic substrates and the pyrene functionalities. ${ }^{[9-10]}$ Based on these precedents, we now prepared to new pyrene-tagged rhodium NHC complexes, which we used as catalysts in the addition of arylboronic acids to cyclohexanone, and in the hydrosilylation of terminal alkynes. These two catalysts were immobilized onto reduced graphene oxide ( $\mathrm{rGO}$ ), and the activities and recyclability properties of the resulting heterogeneized catalysts were studied for the same two processes.

\section{Results and Discussion}

The imidazolium and bis-azolium salts $\mathbf{A}$ and $\mathbf{B}$ were prepared according to the literature procedures. ${ }^{[11]}$ The coordination to rhodium, was performed according to the method depicted in Scheme 1. The reaction of the imidazolium or bisazolium salts $\mathbf{A}$ or $\mathbf{B}$ with $[\mathrm{RhCl}(\mathrm{COD})]_{2}$ in a mixture of THF/DMF at $80^{\circ} \mathrm{C}$ in the presence of $\mathrm{K}_{2} \mathrm{CO}_{3}$ gave complexes 1 and 2 . $\mathrm{KBr}$ was added to the reaction mixture in order to facilitate the formation of the bromide containing complexes and avoid the presence of mixtures of halides in the reaction products. The resulting 
products, 1 and 2, were obtained in moderate-high yields (56$65 \%)$ after workup.
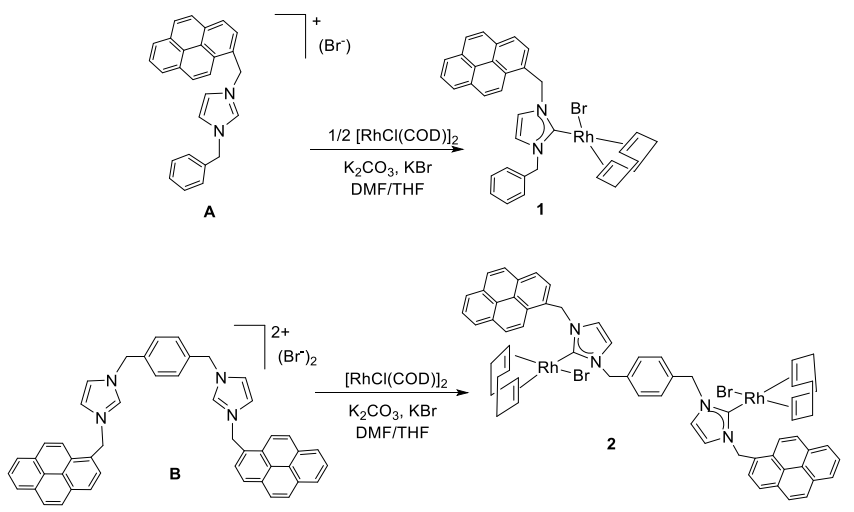

Scheme 1. Preparation of compounds 1 and 2

Both complexes were characterized by means of NMR spectroscopy and Mass Spectrometry, and gave satisfactory elemental analysis. The ${ }^{13} \mathrm{C}$ NMR of complexes 1 and $\mathbf{2}$, show the distinctive doublets due to the metallated carbene carbons at 183.6 ( ${ }^{1} \mathrm{JRh}-\mathrm{C}=50 \mathrm{~Hz}$ ), and $183.4\left({ }^{1} \mathrm{JRh}-\mathrm{C}=50 \mathrm{~Hz}\right) \mathrm{ppm}$. Both ${ }^{1} \mathrm{H}$ and ${ }^{13} \mathrm{C}$ NMR spectra of complex 2 are in agreement with its twofold symmetry. The ESI-mass spectrometry of the complexes shows representative peaks at $\mathrm{m} / \mathrm{z}$ values of 583.2 (assigned to $\left.[1-\mathrm{Br}]^{+}\right)$, complexes at $1169.2(\text { assigned to[2-Br] }]^{+}$).
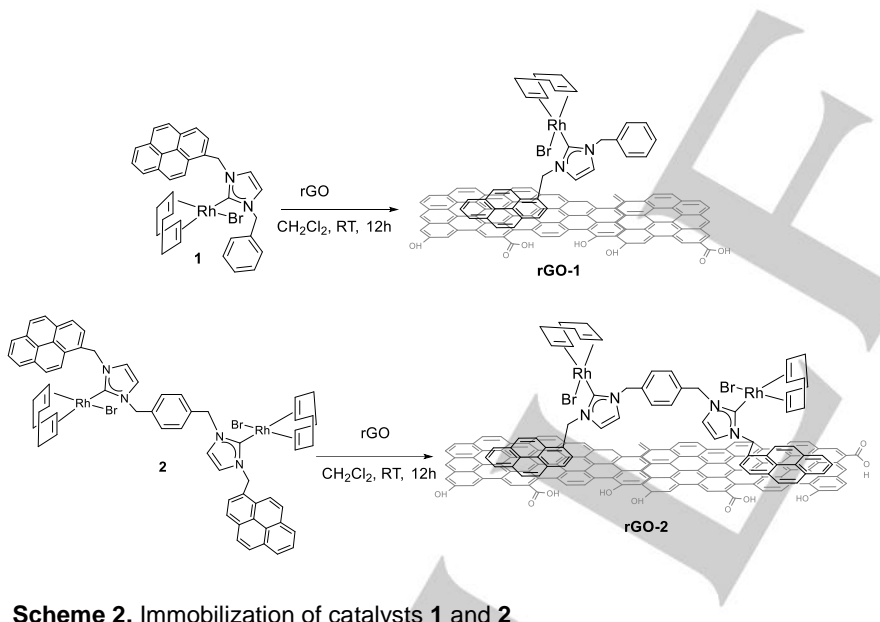

Scheme 2. Immobilization of catalysts 1 and 2

Complexes 1 and 2 were grafted onto reduced graphene oxide ( $\mathrm{rGO}$ ) by mixing complexes $\mathbf{1}$ or $\mathbf{2}$ and rGO in dichloromethane in an ultrasound bath for $20 \mathrm{~min}$. Then, the suspension was stirred during $12 \mathrm{~h}$ (Scheme 2). The first visual evidence of the anchoring of the catalysts onto the solid is the disappearance of the yellow color of the solution. The resulting black solids were filtered and washed with methylene chloride. The ${ }^{1} \mathrm{H}$ NMR spectra of the filtrate confirmed the absence of signals due to $\mathbf{1}$ or $\mathbf{2}$ in the solution, thus constituting an evidence of the effective immobilization of the molecular complexes on the solid. The exact rhodium content in solids rGO-1 and rGO-2 was determined by digestion of the samples in hot $\mathrm{HCl} / \mathrm{HNO}_{3}$ followed ICP-MS analysis, and accounted for a 0.9 and $1.11 \mathrm{wt} \%$ of rhodium in rGO-1and rGO-2, respectively. The elemental mapping by energy-dispersive X-ray spectroscopic analysis (EDS) performed by means of High Resolution Transmission Electron Microscopy (HRTEM) of rGO-2 confirmed the homogeneous distribution of rhodium in the hybrid material (Figure 1 shows the HRTEM and EDS elemental mapping images obtained for rGO-2).
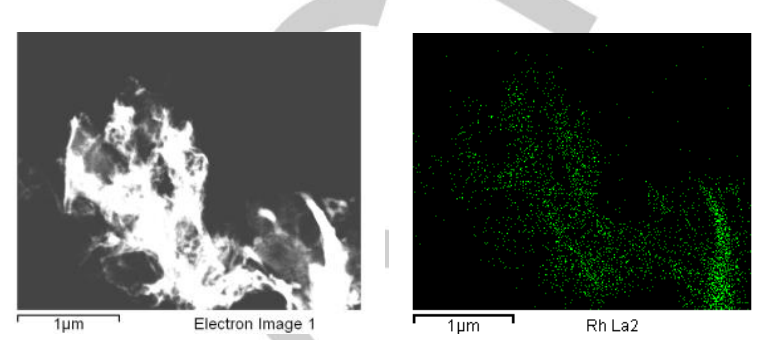

Figure 1. STEM image (left), and EDS (HRTEM) elemental mapping image of rGO-2 (right; green dots indicate rhodium atoms).

The catalytic activity of complexes $\mathbf{1}$ and $\mathbf{2}$ was tested in two reactions typically catalyzed by rhodium (I) complexes, namely the 1,4-addition of arylboronic acids to cyclohexen-2-one, and in the hydrosilylation of terminal alkynes. The two ligands in $\mathbf{1}$ and $\mathbf{2}$ induce quasi-identical stereoelectronic properties, and therefore the comparison of the activities of these two complexes offer an excellent opportunity to compare the activity of the dimetallic complex with respect to its monometallic analogue. The activity of the heterogeneized materials rGO-1 and rGO-2 will also be compared with the one shown by their homogeneous counterparts.

The addition of arylboronic acids to $\alpha, \beta$-unsaturated ketones, $\left.{ }^{[12]}\right]$ is a process for which some $\mathrm{Rh}(\mathrm{I})-\mathrm{NHC}$ complexes have afforded excellent activities and chemoselectivities. ${ }^{[12 a, 13]}$ As a model reaction, we studied the addition of phenyl boronic acid to cyclohexen-2-one. The reactions were carried out using equimolecular amounts of phenylboronic acid and cyclohexanone, during 6 hours in toluene at $100^{\circ} \mathrm{C}$ in the presence of $\mathrm{KOH}$. The catalyst loading was 0.2 mol\% for 1 and $0.1 \mathrm{~mol} \%$ for 2 , in order to study the reactions using the same amount of rhodium load. Under these reaction conditions, catalyst 1 yielded $85 \%$ of the final product, while the dimetallic catalyst 2 afforded almost quantitative yields (98\%). This result contrasts with our previous finding that a trimetallic NHC-based rhodium catalyst afforded quasi-identical activities as its related monometallic analogue for this same catalytic reaction. ${ }^{[13 \mathrm{~d}]}$ In this case, we believe that the presence of the pyrene functionalities in the rhodium catalysts may have some influence in the activity of the catalysts due to possible $\pi$-stacking interactions with the aromatic substrates, and this may induce substantial differences with the activities shown by related rhodium catalysts not containing pyrene tags. ${ }^{[9]} \mathrm{Next}$, we studied the activities of the hybrid materials rGO-1 and rGO-2 in the same reaction. Each individual run was carried out using a $0.2 \mathrm{~mol} \%$ based on rhodium load (the amount of solid was calculated based on the amount of rhodium determined by ICP- 
MS). After completion of each run (6 hours), the solid was filtered, washed with $\mathrm{CH}_{2} \mathrm{Cl}_{2}$ and reused in the following run.
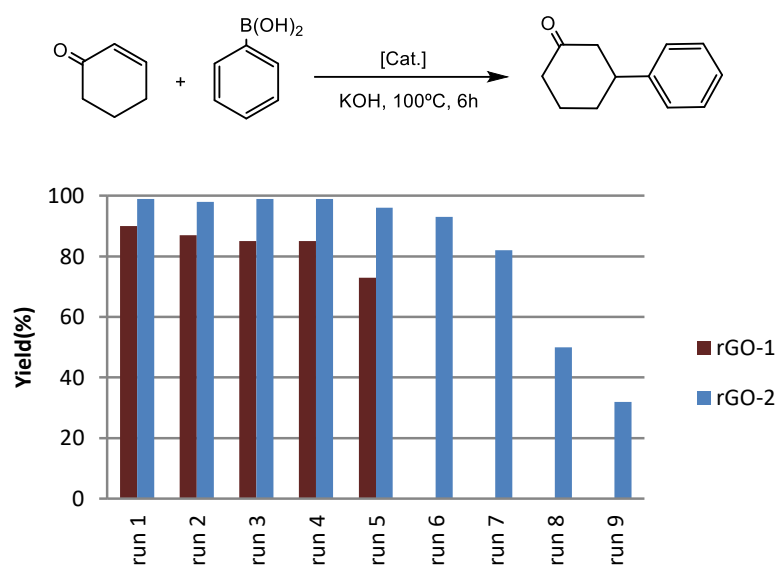

Figure 2. Recycling experiments of the 1,4-addition of phenyl boronic acid to cyclohexen-2-one. Reaction conditions: 2-cyclohexen-1-one $(0.5 \mathrm{mmol})$, arylboronic acid $(0.6 \mathrm{mmol}), \mathrm{KOH}(0.09 \mathrm{mmol})$ and $\mathrm{rGO}-1$ or rGO-2 $(0.2 \mathrm{~mol} \%$ based on the metal) toluene $(1.5 \mathrm{~mL})$ at $100^{\circ} \mathrm{C}$ for $6 \mathrm{~h}$. Yields determined by GC using anisole as internal standard.

As can be observed from the results shown in Figure 2, both catalysts rGO-1 and rGO-2 showed similar catalytic activities as their homogeneous counter-parts in the first cycle. Catalyst rGO1 gradually diminished its activity during five cycles (from $90 \%$ to $73 \%$ yield), and then the activity abruptly ceased. The activity of rGO-2 was maintained higher than that shown by rGO-1 all along the recyclability experiments. During the first four cycles rGO-2 produced quantitative yields of the final product, and then the activity gradually decreased until the complete deactivation of the catalyst after the $9^{\text {th }}$ run. Considering the accumulated turnover numbers of these recyclability experiments, the results shown here constitute a clear enhancement of the catalytic activity of the hybrid materials compared to the results shown in homogeneous conditions. In particular, catalyst rGO-2 accumulated 3500 turnovers. The fact that the dimetallic complex with the twopyrene tags affords higher activity and better recyclability properties than the catalyst with only one pyrene tag is in accordance with previous studies, which suggest that leaching is significantly reduced when the metal complex is anchored to the surface of the solid by more than one pyrene tag. ${ }^{[4 \mathrm{~b}, 9]}$

The solids resulting from the recycling experiments were analyzed by means of HRTEM spectroscopy and ICP-MS. The ICP-MS analysis of the solids revealed that the rhodium content for rGO-1 and rGO-2 was $0.73 \%$ and $1.11 \%$, respectively, therefore there was a $30 \%$ loss of rhodium after all five cycles in the case of rGo-1, while the amount of metal was maintained all over the 9 cycles in the case of rGO-2. As previously mentioned, this is in agreement with our previous findings regarding the more effective immobilization of catalysts containing two pyrene-tags compared to those containing only one pyrene-tag. . $^{[9]}$ The HRTEM images (see SI for details), did not show any traces of formation of metal nanoparticles, and the EDS analysis revealed that the homogeneous distribution of rhodium along the solid surface was maintained. The morphology of graphene does not show significant changes compared to the original one, apart from an increase in the number of wrinkles. Taking all these results together, we believe that the loss of activity of the catalysts may be due to partial loss of bulk hybrid catalyst during the filtration process after each run, combined with the partial poisoning of the surface of the catalyst by the addition of $\mathrm{KOH}$ for each of the cycles of the experiment.

Next we studied the activity of the rhodium complexes $\mathbf{1}$ and $\mathbf{2}$ and their hybrid heterogeneized analogues, rGO-1 and rGO-2, in the hydrosilylation of terminal alkynes. This reaction constitutes a good challenge for study, because the search for an effective catalyst requires that the catalyst not only affords a high activity, but also high selectivity toward one of the three possible isomers that can be obtained. Several rhodium complexes have provided good activities and selectivities in this reaction with important practical applications in synthetic organic chemistry. ${ }^{[14]}$

Table 1. Hydrosilylation of terminal alkynes using catalysts 1 and 2

\begin{tabular}{|c|c|c|c|c|c|c|}
\hline $\begin{array}{c}\text { Entr } \\
y\end{array}$ & $\begin{array}{c}\text { Catalys } \\
\mathrm{t}\end{array}$ & alkyne & $\begin{array}{c}\beta(Z) \\
a\end{array}$ & $\alpha^{a}$ & $\underset{a}{\beta(E)}$ & $\underset{\mathrm{a}}{\text { Conversion }}$ \\
\hline 1 & 1 & hexyne & 56 & 6 & 27 & 89 \\
\hline 2 & 2 & hexyne & 69 & 2 & 17 & 86 \\
\hline $3^{b}$ & 1 & $\begin{array}{l}\text { phenylacetylene } \\
\text { * }\end{array}$ & 17 & $\begin{array}{l}0 . \\
8\end{array}$ & 14 & 46 \\
\hline $4^{b}$ & 2 & $\begin{array}{l}\text { phenylacetylene } \\
*\end{array}$ & 56 & $\begin{array}{l}2 . \\
3\end{array}$ & 15 & 86 \\
\hline
\end{tabular}

Reaction conditions: $0.077 \mathrm{mml}$ of alkyne and $0.085 \mathrm{mmol}$ of $\mathrm{HSiMe}_{2} \mathrm{Ph}$ in 0.5 $\mathrm{mL}$ of $\mathrm{CDCl}_{3}$, at room temperature during $6 \mathrm{~h} .2 \mathrm{~mol} \%$ of catalyst loading, based on the rhodium content. ${ }^{a}$ Yields and conversions determined by ${ }^{1} \mathrm{H}$ NMR spectroscopy, using anisole as internal standard. ${ }^{\mathrm{b}} \mathrm{A}$ small amount of styrene was observed together with all other reaction products.

We first studied the homogeneously catalyzed reactions between 1-hexyne and phenylacetylene with $\mathrm{HSiMe}_{2} \mathrm{Ph}$. The reactions were performed in $\mathrm{CDCl}_{3}$ at room temperature using catalyst loadings of $2 \mathrm{~mol} \%$ (based on rhodium concentration). Under these reaction conditions, both catalysts showed good activity in the hydrosililation of 1-hexyne, with a clear preference for the formation of the anti-Markovnikov anti-addition $\beta(Z)$ vinylsilane product, which reaches $69 \%$ yield when the dimetallic catalyst 2 was used (Table 1, entry 2 ). This observation is very interesting, because the $\beta(Z)$ is the less frequent product in this reaction, and thus a very elusive target. ${ }^{[14 c, d, 15]}$ Catalyst 2 is more active than catalyst 1 in the hydrosilylation of phenylacetylene with $\mathrm{HSiMe}_{2} \mathrm{Ph}$, and also more selective in the production of the $\beta-(Z)$ vinylsilane ( $56 \%$ yield, entry 4 ). For this reaction, we observed that the conversion was slightly higher than the sum of the product yields when catalyst 2 was used. This is because together with the formation of the three vinylsilanes, we observed the formation of styrene, a clear indication that the hydrosilylation of the terminal alkyne was accompanied by the dehydrogenative silylation, with styrene formed as hydrogen-trapping agent. The product resulting 
from the dehydrogenative silylation (in our case $\mathrm{PhC} \equiv \mathrm{CSiMe}{ }_{2} \mathrm{Ph}$ ) is easy to miss when the reaction is followed by ${ }^{1} \mathrm{H}$ NMR, and the formation of styrene is the clearest indication that this process is occurring. ${ }^{[14 g, 16]}$

Because we wanted to have a complete picture of the product formation along the course of the reaction, we studied the timedependent reaction profiles of the hydrosilylation reactions. As can be seen from the graphics shown in Figure 3 , the ratio between the three isomers formed in the process is maintained all along the reaction course. This discards that any of the reaction products are formed via the metal-assisted isomerization of any of the other vinylsilanes. ${ }^{[14 e, 17]}$ Interestingly, the reaction profiles arising from the evolution of the reactions of 1-hexyne with $\mathrm{HSiMe}_{2} \mathrm{Ph}$ show the curved profiles typical for a process that follows a first order reaction with respect to the concentration of the alkyne. A different situation arises from the analysis of the plots referred to the evolution of the reaction of phenylacetylene with the silane. For these processes, the reaction course is represented by a straight line, indicating that the reaction is pseudo-zeroth order with respect to the concentration of the substrate, and therefore the reaction rate does not depend on the concentration of phenylacetylene. This type of situation normally arises when only a small portion of molecules of the substrate are in a location where they are able to react, and this fraction is continually replenished from the larger pool. We previously found that this situation is produced when using pyrene-tagged catalysts and aromatic substrates. We attributed the effect to the noncovalent interaction between the aromatic substrate and the pyrene-tag of the catalyst, which saturates the catalyst, and renders a reaction rate that is non-dependent on the concentration of the substrate..$^{[9]}$
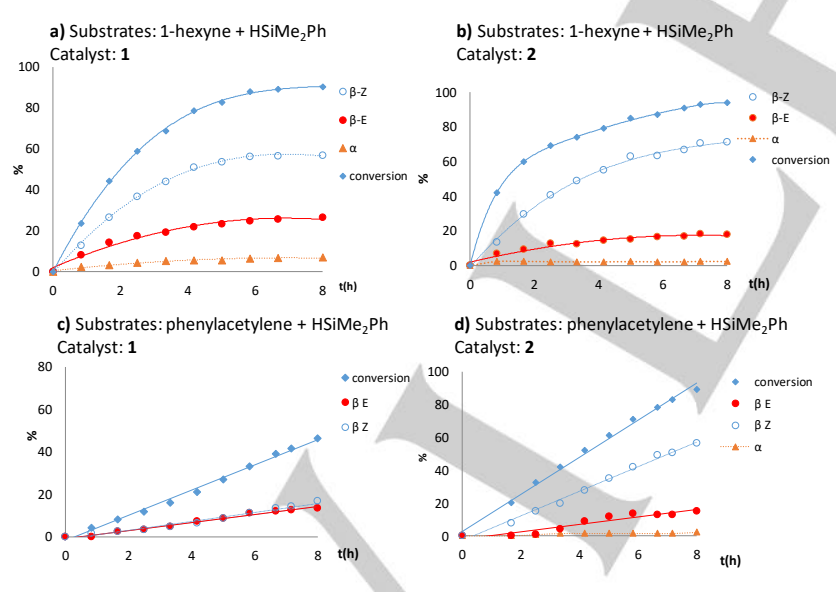

Figure 3. Time-dependent reaction profiles of the reactions of 1-hexyne and phenylacetylene with $\mathrm{HSiMe}_{2} \mathrm{Ph}$ using catalysts $\mathbf{1}$ and 2 . Reaction conditions: $0.077 \mathrm{mml}$ of alkyne and $0.085 \mathrm{mmol}$ of $\mathrm{HSiMe}_{2} \mathrm{Ph}$ in $0.5 \mathrm{~mL}$ of $\mathrm{CDCl}_{3}$, at room temperature with 2 mol\% of catalyst loading (based on rhodium content). a) 1-hexyne + $\mathrm{HSiMe}_{2} \mathrm{Ph}$ using catalyst1, b) 1-hexyne + $\mathrm{HSiMe}_{2} \mathrm{Ph}$ using catalyst $2, \mathrm{c}$ ) phenylacetylene $+\mathrm{HSiMe}_{2} \mathrm{Ph}$ using catalyst 1 and, d) phenylacetylene $+\mathrm{HSiMe}_{2} \mathrm{Ph}$ using catalyst 2 .
We next studied the activity of the hybrid materials rGO-1 and rGO-2 in the hydrosilylation of 1-hexyne and phenylacetylene. The study of these reactions under heterogeneous conditions allows to compare the activity and selectivity of the solid materials with the ones provided by the homogeneous catalysts, and to determine the recyclability properties of the heterogeneized catalysts. The studies of the heterogeneization and reutilization of alkyne hydrosilylation catalysts are very rare, although Messerle and co-workers recently described an interesting example in which a $\mathrm{Rh}(\mathrm{I})-\mathrm{NHC}$ based complex was covalently immobilized onto graphene, and afforded excellent activities and high reusability in the hydrosilylation of diphenylacetylene. ${ }^{[18]} \mathrm{We}$ performed the reactions in $\mathrm{CDCl}_{3}$ using a $2 \mathrm{~mol} \%$ of catalyst loading. While we observed that the reactions at room temperature did not show any significant product formation after $8 \mathrm{~h}$, the reactions at $60^{\circ} \mathrm{C}$ produced conversions above $80 \%$ after $6 \mathrm{~h}$. Figure 4 shows the results for the reactions performed between phenylacetylene and $\mathrm{HSiMe}_{2} \mathrm{Ph}$ using catalysts rGO-1 and rGO-2. The reaction performed in the presence of rGO-1 afforded $85 \%$ conversion, with the $\beta(Z)$ vinylsilane being the major product formed (61\% yield). Both $\beta(E)$ and $\alpha$ isomers were obtained with yields below $20 \%$. In terms of selectivity, this result is in perfect accordance with the results provided by the homogeneous catalyst $\mathbf{2}$. After the first run finished, the solid was filtered, washed with $\mathrm{CH}_{2} \mathrm{Cl}_{2}$ and reused for a second cycle. In the second run, the activity of rGO-1 dropped down to only $17 \%$ conversion, with the same relative proportion of vinylsilanes formed. The activity of catalyst rGO-2 (87\% conversion, $61 \%$ yield of $\beta(Z)$ ) was very similar to that shown by rGO-1 during the first run. However, this catalyst could be reused a second time without loss of activity, showing the same relative formation of isomers as in the first cycle. The activity of the catalyst was gradually reduced during the third (58\% conversion) and fourth cycles (32\% conversion), and was negligible in the fifth run.
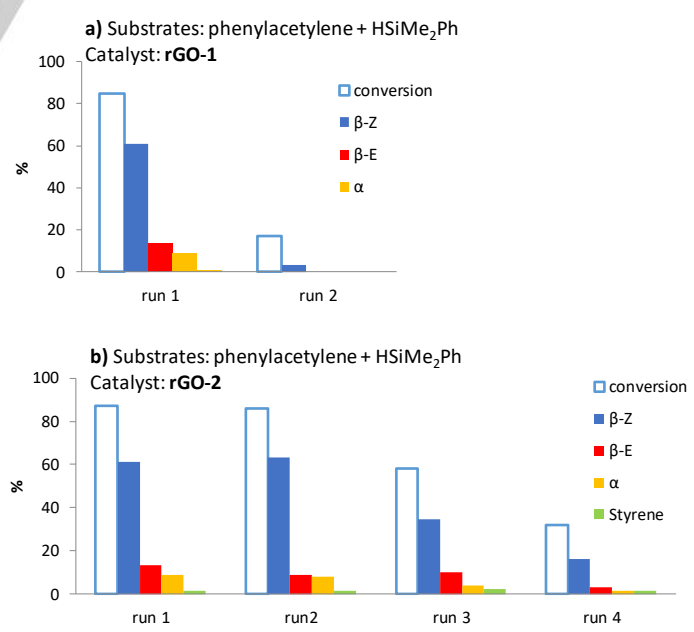

Figure 4.Recycling experiments of the reaction of phenylacetylene with HSiMe 2 Ph using hybrid catalysts rGO-1 (a) and rGO-2 (b). Reaction conditions: alkyne $(0.077 \mathrm{mmol}), \mathrm{HSiMe}_{2} \mathrm{Ph}(0.085 \mathrm{mmol})$, and rGO-1 or rGO-2 $(2 \mathrm{~mol} \%$ based on rhodium) in $\mathrm{CDCl}_{3}(0.5 \mathrm{~mL})$ at $60^{\circ} \mathrm{C}$ during $8 \mathrm{~h}$. Conversions and yields determined by ${ }^{1} \mathrm{H}$ NMR spectroscopy using anisole as standard. 
Given the higher activity and reusability properties of catalyst rGO-2, we decided to study the activity of this catalyst in the hydrosilylation of 1-hexyne. The results are shown in Figure 5. The analysis of the results allowed extracting two interesting conclusions. First, the catalyst showed good activity during the first cycle $(71 \%$ conversion), and then the activity was gradually reduced until the $6^{\text {th }}$ run ( $6 \%$ conversion). Second, the selectivity of the catalyst toward the production of the $\beta(Z)$-vinylsilane was clearly enhanced compared to the homogeneous catalyst $\mathbf{2}$, as can be observed from the very little differences shown between the conversion values and the yields of production of this isomer. In fact, we did not detect the formation of any other vinylsilanes during any of the cycles performed in this series of experiments. Given that the $\beta(Z)$-vinylsilane is a very elusive and pursued target in the hydroslylation of terminal alkynes, we believe that this result is of major importance.

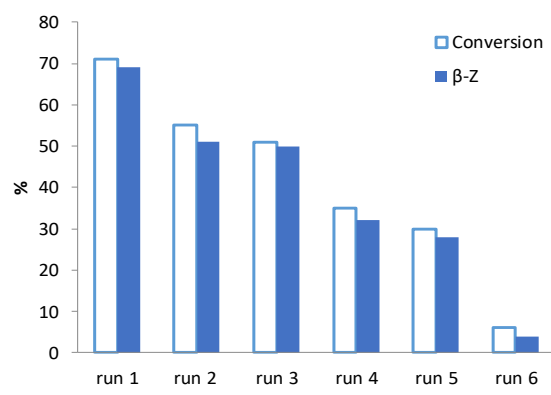

Figure 5.Recycling experiments of the reaction of 1-hexyne with $\mathrm{HSiM}_{2} \mathrm{Ph}$ using hybrid catalyst rGO-2. Reaction conditions: alkyne (0.077 mmol), $\mathrm{HSiMe}_{2} \mathrm{Ph}$ (0.085 mmol), and rGo-2 (1 mol \%) in $\mathrm{CDCl}_{3}(0.5 \mathrm{~mL})$ at $60^{\circ} \mathrm{C}$ during $8 \mathrm{~h}$. Conversions and yields determined by ${ }^{1} \mathrm{H}$ NMR spectroscopy using anisole as standard.

The solids resulting from the recycling experiments were analyzed by means of HRTEM spectroscopy and ICP-MS. The ICP-MS analysis of the rhodium contentin rGO-2 after the recycling experiments was 1.08 and $1.10 \%$, for the hydrosilylations of phenylacetylene and 1-hexyne, respectively. These results indicate that the dimetallic catalyst is effectively supported onto the solid, and that for rGO-2 leaching is negligible after all recycling experiments. On the contrary, for the monometallic catalyst, with only one pyrene functionality, the final rhodium content was $0.8 \%$, thus indicating a $15 \%$ loss of rhodium after only two recycling experiments. This result is in agreement with the fact that the immobilization of the monometallic catalyst is much less efficient than for the catalyst containing two pyrene functionalities.

The HRTEM images (see SI for details), did not show traces of formation of nanoparticles. The EDS analysis revealed that the homogeneous distribution of rhodium along the solid surface was maintained. The morphology of graphene does not show significant changes compared to the original one. Taking all these result together, we believe that the loss of activity of the catalysts may be due the partial poisoning of the surface of the catalyst by the reagents.

\section{Conclusions}

In summary, we prepared two rhodium(l) catalysts with $\mathrm{N}$ heterocyclic carbene ligands decorated with pyrene functionalities. The two catalysts were immobilized on the surface of reduced graphene oxide (rGO), and the catalytic activity of the homogeneous catalysts and the solids were compared, in two organic transformations: the 1,4-addition of phenylboronic acid to cyclohexan-4-one, and in the hydrosilylation of terminal alkynes. In both catalytic reactions, the dimetallic complex showed better catalytic performances than the monometallic one. For the reactions carried out with the heterogeneized catalysts, we observed that the dimetallic catalyst with the two pyrene functionalities displayed higher catalytic activity than the material with the catalyst containing only one pyrene tag. The solid containing the dimetallic catalyst could be effectively recycled for five times without measurable loss of activity in the addition of phenylboronicacid to cyclohexanone. In the case of the hydrosilylation of terminal alkynes, the solid containing the dimetallic catalyst afforded a clear improvement on the selectivity of the process, with the reaction being stereoselective in the production of the $\beta(Z)$-vinylsilane for the case of the hydrosilylation of 1 -hexyne. This result is very interesting, because it indicates that the immobilization of the catalyst onto rGO not only can afford catalysts that can be effectively reused, but also that the selectivity may be improved.

The analysis of the solids after the recycling experiments, indicated that leaching was negligible for the catalysts with two pyrene fragments, while there was an important loss of rhodium content for the material containing the catalyst with only one pyrene tag. These results illustrate how the effectiveness of the immobilization is clearly dependent on the number of anchoring pyrene sites on the catalyst.

\section{Experimental Section}

General comments. All manipulations were carried out under nitrogen using standard Schlenk techniques and high vacuum. Anhydrous solvents were either distilled from appropriate drying agents (SPS) and degassed prior to use by purging with dry nitrogen and kept over molecular sieves. The azolium salts 2, 3 and 4 were obtained according to the procedures reported in the literature. ${ }^{[11]}$ All other reagents were used as received from commercial suppliers. NMR spectra were recorded on Varian spectrometers. Electrospray mass spectra (ESI-MS) were recorded on MicromassQuatro LC instrument, and nitrogen was employed as drying and nebulizing gas. A gas chromatograph GC-2010 (Shimadzu) equipped with a FID and Technokroma (TRB-5MS, $30 \mathrm{~m} \times 0.25 \mathrm{~mm} \times 0.25 \mu \mathrm{m}$ ) column and a gas chromatograph/mass spectrometer GCMS- QP2010 (Shimadzu) equipped with a Technokroma (TRB-5MS, $30 \mathrm{~m} \times 0.25 \mathrm{~mm}$ x $0.25 \mu \mathrm{m}$ ) column were used. Elemental analyses were carried out in an EA 1108 CHNS-O Carlo Erbaanalyzer. Electrospray mass spectra (ESIMS) were recorded on a MicromassQuatro LC instrument, and nitrogen was employed as drying and nebulizing gas. High-resolution transmission electron microscopy images (HRTEM) and high-angle annular dark-field HAADF-STEM images of the samples were obtained using a Jem-2100 LaB6 (JEOL) transmission electron microscope coupled with an INCA Energy TEM 200 (Oxford) energy-dispersive X-ray spectrometer (EDX) operating at $200 \mathrm{kV}$. Varian spectrophotometer. The determination of the metal loading was done by ICP-MS Agilent $7500 \mathrm{CX}$. 


\section{Synthesis and characterization of rhodium complexes}

Synthesis of 1. A mixture of salt $\mathbf{A}(70.0 \mathrm{mg}, 0.16 \mathrm{mmol}),[\mathrm{RhCl}(\mathrm{COD})]_{2}$ (39.4 mg, $0.08 \mathrm{mmol}), \mathrm{K}_{2} \mathrm{CO}_{3}(67.0 \mathrm{mg}, 0.48 \mathrm{mmol})$ and $\mathrm{KBr}(70.0 \mathrm{mg})$ in THF/DMF $(7: 2 \mathrm{~mL})$ was stirred at $75^{\circ} \mathrm{C}$ for $8 \mathrm{~h}$. The reaction was carried under $\mathrm{N}_{2}$. The resulting suspension was cooled to room temperature and the solvent was removed under vacuum. The pure compound 1 was precipitated in a mixture of dichloromethane/hexane to give a yellow solid. Yield: $56 \%(60.0 \mathrm{mg}) .{ }^{1} \mathrm{H} \mathrm{NMR}\left(300 \mathrm{MHz}, \mathrm{CDCl}_{3}\right) \delta 8.53\left(\mathrm{~d},{ }^{3} \mathrm{HH}=9.3 \mathrm{~Hz}\right.$, $\left.1 \mathrm{H}, \mathrm{CH}_{\text {pyrene) }}\right), 8.32-8.14$ ( $\left.\mathrm{m}, 4 \mathrm{H}, \mathrm{CH}_{\text {pyrene }}\right), 8.06$ ( $\left.\mathrm{m}, 4 \mathrm{H}, \mathrm{CH}_{\text {pyrene }}\right), 7.37$ $\left(\mathrm{m}, 5 \mathrm{H}, \mathrm{CH}\right.$ Ph), $6.69\left(\mathrm{~d},{ }^{2}{ }^{\mathrm{HH}}=14.8 \mathrm{~Hz}, 1 \mathrm{H}, \mathrm{CH}_{2}\right), 6.59\left(\mathrm{~d},{ }^{2} \mathrm{~J}_{\mathrm{HH}}=1.9 \mathrm{~Hz}\right.$, $1 \mathrm{H}, \mathrm{CH}$ imidazole), $6.46\left(\mathrm{~d},{ }^{2} \mathrm{~J}_{\mathrm{HH}}=2.0 \mathrm{~Hz}, 1 \mathrm{H}, \mathrm{CH}\right.$ imidazole $), 6.33\left(\mathrm{~d},{ }^{2} \mathrm{JHH}_{\mathrm{HH}}=14.8\right.$ $\left.\mathrm{Hz}, 1 \mathrm{H}, \mathrm{CH}_{2}\right), 5.87$ (dd, $\left.{ }^{2} \mathrm{JH}_{\mathrm{H}}=2.6 \mathrm{~Hz}, 2 \mathrm{H}, \mathrm{CH}_{2}\right), 5.23\left(\mathrm{~s}, 2 \mathrm{H}, \mathrm{CH}, \mathrm{CH} H_{\mathrm{cod}}\right)$ 3.58 ( $\left.\mathrm{m}, 1 \mathrm{H}, \mathrm{C} H_{\mathrm{COD}}\right), 3.48\left(\mathrm{~m}, 1 \mathrm{H}, \mathrm{CH} H_{\mathrm{COD}}\right), 2.47-2.12\left(\mathrm{~m}, 4 \mathrm{H}, \mathrm{CH}_{2, \mathrm{COD}}\right)$, $1.89\left(\mathrm{~m}, 4 \mathrm{H}, \mathrm{CH}_{2}, \mathrm{COD}\right) .{ }^{13} \mathrm{C} \mathrm{NMR}\left(75 \mathrm{MHz}, \mathrm{CDCl}_{3}\right) \delta 183.4\left(\mathrm{~d},{ }^{1} \mathrm{~J}=5 \mathrm{OHz}\right.$,

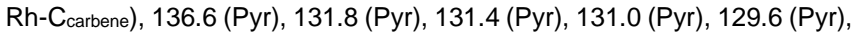
129.0 (Pyr), 128.8 (Pyr), 128.1 (Pyr), 127.6 (Pyr), 127.5 (Pyr), 126.4 (Pyr), $125.8\left(\mathrm{CPh}_{\mathrm{Ph}}\right), 125.1\left(\mathrm{CPh}_{\mathrm{Ph}}\right), 124.7\left(\mathrm{CH}_{\mathrm{Ph}}\right), 123.3\left(\mathrm{CH}_{\mathrm{Ph}}\right), 121.3\left(\mathrm{CH}_{\text {imidazole }}\right)$, 120.7 ( $\left.\mathrm{CH}_{\text {imidazole }}\right), 98.83$ ( $\left.\mathrm{CH}_{\mathrm{COD}}\right), 98.6$ ( $\left.\mathrm{CH}_{\text {COD }}\right), 76.7,69.7$ ( $\left.\mathrm{CH}_{\text {COD }}\right), 69.6$ (CHCOD), 69.4 (CHCOD), $54.60\left(\mathrm{CH}_{2}\right), 52.8\left(\mathrm{CH}_{2}\right), 33.0\left(\mathrm{CH}_{2, \mathrm{COD}}\right), 32.8$ $\left(\mathrm{CH}_{2, \mathrm{COD}}\right), 29.2\left(\mathrm{CH}_{2, \mathrm{COD}}\right), 29.1 \quad\left(\mathrm{CH}_{2, \mathrm{COD}}\right)$. Anal.Calcd.for $\mathrm{C}_{35} \mathrm{H}_{32} \mathrm{~N}_{2} \mathrm{BrRh} \cdot \mathrm{CHCl}_{3}$ (782.8291): C, 55.23; H, 4.24; N, 3.57. Found: C, $55.27 ; \mathrm{H}, 4.15 ; \mathrm{N}, 3.29$. Electrospray MS (Cone $20 \mathrm{~V})$ (m/z, fragment): $583.2[\mathrm{M}-\mathrm{Br}]^{+}$

Synthesis of 2. A mixture of $\mathbf{B}(80.0 \mathrm{mg}, 0.10 \mathrm{mmol})$, [RhCl(COD) $]_{2}(49.3$ $\mathrm{mg}, 0.10 \mathrm{mmol}), \mathrm{K}_{2} \mathrm{CO}_{3}(82.9 \mathrm{mg}, 0.6 \mathrm{mmol})$ and $\mathrm{KBr}(70.0 \mathrm{mg})$ in THF/DMF $(10: 3 \mathrm{~mL})$ was stirred at $75^{\circ} \mathrm{C}$ for $8 \mathrm{~h}$. The reaction was carried under $\mathrm{N}_{2}$. The resulting suspension was cooled to room temperature and the solvent was removed under vacuum. The crude product was purified by column chromatography. The pure compound 2 was eluted with dichloromethane: ethyl acetate (8:2) and precipitated in a mixture of dichloromethane/hexane to give a yellow solid. Yield: $65 \%(90.2 \mathrm{mg}) .{ }^{1} \mathrm{H}$ $\operatorname{NMR}\left(300 \mathrm{MHz}, \mathrm{CDCl}_{3}\right) \delta 8.53\left(\mathrm{~d},{ }^{3} \mathrm{JHH}=9.3 \mathrm{~Hz}, 2 \mathrm{H}, \mathrm{CH}_{\text {pyr }}\right), 8.24-8.08$ (m, $16 \mathrm{H}, \mathrm{CH}_{\text {pyr }}, 7.47$ (s, 4H, CHph), 6.67 (d, J=14.7 Hz, 2H, CH), 6.58 (d, $J=2.0 \mathrm{~Hz}, 1 \mathrm{H}, \mathrm{CH}), 6.57(\mathrm{~d}, J=1.9 \mathrm{~Hz}, 1 \mathrm{H}, \mathrm{CH}), 6.47(\mathrm{~d}, J=1.8 \mathrm{~Hz}, 1 \mathrm{H}$, $\mathrm{CH}), 6.44(\mathrm{~d}, J=1.9 \mathrm{~Hz}, 1 \mathrm{H}, \mathrm{CH}), 6.34(\mathrm{~d}, J=14.7 \mathrm{~Hz}, 1 \mathrm{H}, \mathrm{CH}), 6.32(\mathrm{~d}$, $J=14.7 \mathrm{~Hz}, 1 \mathrm{H}, \mathrm{CH}), 6.01(\mathrm{~d}, J=14.9 \mathrm{~Hz}, 1 \mathrm{H}, \mathrm{CH}), 5.95(\mathrm{~d}, J=14.9 \mathrm{~Hz}$, $1 \mathrm{H}, \mathrm{CH}), 5.78(\mathrm{~d}, J=14.9 \mathrm{~Hz}, 1 \mathrm{H}, \mathrm{CH}), 5.72(\mathrm{~d}, J=14.9 \mathrm{~Hz}, 1 \mathrm{H}, \mathrm{CH}), 5.22$ (m, 4H, CHCOD), $3.56\left(\mathrm{~m}, 2 \mathrm{H}, \mathrm{C} H_{\text {COD }}\right), 3.47$ (m, 2H, CHCOD), $2.25(\mathrm{~m}, 2 \mathrm{H}$, CHCOD), $2.00-1.71\left(\mathrm{~m}, 4 \mathrm{H}, \mathrm{CH}_{2, \mathrm{COD}}\right), 1.56\left(\mathrm{~m}, 4 \mathrm{H}, \mathrm{CH}_{2, \mathrm{COD}}\right) \cdot{ }^{13} \mathrm{C} \mathrm{NMR}(75$ $\left.\mathrm{MHz}, \mathrm{CDCl}_{3}\right) \delta 180.8$ (C Carbene-Ir), 136.3 (Pyr), 131.6 (Pyr), 131.2 (Pyr), 130.7 (Pyr), 129.4 (Pyr), 128.7 (Pyr), 128.4 (Pyr), 127.9 (Pyr), 127.57 (Pyr) 127.23 (Pyr), 126.2 (CPhenylene), 125.6 (CH Phenylene), 124.8( $\left.\mathrm{CH}_{\text {imidazole }}\right)$, 124.5, (Pyr), 123.0 (CHimidazole), 120.6(Pyr), 120.1 (Pyr), 84.8 (CHCoD), 84.6 $\left(\mathrm{CH}_{\mathrm{COD}}\right), 54.0\left(\mathrm{CH}_{2}\right), 53.0\left(\mathrm{CH}_{2, \mathrm{COD}}\right), 52.6\left(\mathrm{CH}_{2, \mathrm{COD}}\right), 52.2\left(\mathrm{CH}_{2}\right), 33.3$ $\left(\mathrm{CH}_{2, \mathrm{COD}}\right)$, 29.7 $\left(\mathrm{CH}_{2, \mathrm{COD}}\right)$. Anal.Calcd.for $\mathrm{C}_{64} \mathrm{H}_{58} \mathrm{~N}_{4} \mathrm{Br}_{2} \mathrm{Rh}_{2} \cdot 2 \mathrm{H}_{2} \mathrm{O}(1284.13)$ : C, 59.8; H, 4.9; N, 4.3. Found: C, 59.2; H, 4.9; N, 4.3. Electrospray MS (Cone 20V) (m/z, fragment): $1169.2[\mathrm{M}-\mathrm{Br}]^{+}$

Preparation of rGO-1. In a round-bottom flask were introduced $150 \mathrm{mg}$ of $\mathrm{rGO}$ and $10 \mathrm{~mL}$ of $\mathrm{CH}_{2} \mathrm{Cl}_{2}$. The suspension was sonicated for $30 \mathrm{~min}$. Then, $40 \mathrm{mg}$ of compound6was added. The suspension was stirred at room temperature for $12 \mathrm{~h}$ until the solution become clear. The black solid was filtrated and washed with $2 \times 25 \mathrm{~mL}$ of $\mathrm{CH}_{2} \mathrm{Cl}_{2}$, affording the resulting product as a black solid. The filtrates were combined and evaporated to dryness under reduced pressure. Unsupported compound 1 was analyzed by ${ }^{1} \mathrm{H}$ NMR using anisole as internal standard. Integration of the characteristic signal of anisole (-OMe) versus $\left(\mathrm{CH}_{2}\right.$-pyrene) reveals the amount complex that has been deposited on the rGO. The exact amount of complex supported was determined by ICP-MS analysis. ( $0,9 \%$ wt Rh)

Preparation of rGO-2. In a round-bottom flask were introduced $150 \mathrm{mg}$ of $\mathrm{rGO}$ and $10 \mathrm{~mL}$ of $\mathrm{CH}_{2} \mathrm{Cl}_{2}$. The suspension was sonicated for $30 \mathrm{~min}$. Then,
$20 \mathrm{mg}$ of compound $\mathbf{6}$ was added. The suspension was stirred at room temperature for $12 \mathrm{~h}$ until the solution become clear. The black solid was filtrated and washed with $2 \times 25 \mathrm{~mL}$ of $\mathrm{CH}_{2} \mathrm{Cl}_{2}$, affording the resulting product as a black solid. The filtrates were combined and evaporated to dryness under reduced pressure. Unsupported compound 2 was analyzed by ${ }^{1} \mathrm{H}$ NMR using anisole as internal standard. Integration of the characteristic signal of anisole $(-\mathrm{OMe})$ versus $\left(\mathrm{CH}_{2}\right.$-pyrene) reveals the amount complex that has been deposited on the rGO. The exact amount of complex supported was determined by ICP-MS analysis. (1.11\% wt Rh)

General procedure for the1,4-addition of arylboronic acids to cyclohex-2-one. In a $10 \mathrm{~mL}$ high-pressure Schlenk tube, catalyst $(0.2$ $\mathrm{mol} \%)$, 2-cyclohexen-1-one (0.5 mmol), arylboronic acid $(0.6 \mathrm{mmol}), \mathrm{KOH}$ $(0.09 \mathrm{mmol})$, and dry toluene $(2 \mathrm{~mL})$ were placed. The mixture was stirred and heated to $100^{\circ} \mathrm{C}$ for $6 \mathrm{~h}$. The reaction yields were calculated by GC using anisole as internal standard.

Recycling Experiments. In a round-bottom flask, a mixture of 2 cyclohexen-1-one $(0.5 \mathrm{mmol})$, arylboronic acid $(0.6 \mathrm{mmol}), \mathrm{KOH}(0.09$ $\mathrm{mmol})$ and $\mathrm{rGO}-1$ or rGO-2 $(0.2 \mathrm{~mol} \%$ based on the metal) was refluxed in toluene $(1.5 \mathrm{~mL})$ for $6 \mathrm{~h}$. The monitoring of the reaction, yields, and conversions were determined by GC analyses using anisole as an internal standard. After completion of each run $(6 \mathrm{~h})$, the reaction mixture was allowed to reach room temperature and was filtered. The remaining solid was washed thoroughly with $\mathrm{CH}_{2} \mathrm{Cl}_{2}$, dried under reduced pressure and reused in the following run.

General procedure for the Hydrosilylation of terminal alkynes. In a $\mathrm{nmr}$ tube, a mixture of the alkyne $(0.077 \mathrm{mmol}), \mathrm{HSi}(\mathrm{Me}) \mathrm{Ph}(0.085 \mathrm{mmol})$, and a catalytic amount of 1 or $\mathbf{2}(2 \mathrm{~mol} \%$ based on the metal $)$ were dissolved in $\mathrm{CDCl}_{3}(0.5 \mathrm{~mL})$. The mixture was stirred at room temperature. The progress of the reaction was monitored by ${ }^{1} \mathrm{H}$ NMR spectroscopy. The identity of the products formed was assessed from the literature.

Recycling Experiments. In a $2 \mathrm{~mL}$ vial, a mixture of the alkyne $(0.077$ $\mathrm{mmol}$ ), $\mathrm{HSi}(\mathrm{Me}) \mathrm{Ph}(0.085 \mathrm{mmol}$ ), and the rGO-1 or rGO-2 (2 mol \% based on the metal) were dissolved in $\mathrm{CDCl}_{3}(0.5 \mathrm{~mL})$. The mixture was stirred at $60^{\circ} \mathrm{C}$ for the required time. The monitoring of the reaction, yields, and conversions were determined by $\mathrm{GC}$ analyses using anisole as an internal standard. After completion of each run (6h), the reaction mixture was allowed to reach room temperature and was filtered. The remaining solid was washed thoroughly with $\mathrm{CH}_{2} \mathrm{Cl}_{2}$, dried under reduced pressure and reused for the following run

\section{Acknowledgements}

We gratefully acknowledge financial support from MINECO of Spain (CTQ2014-51999-P) and the Universitat Jaume I (P11B2014-02). We are grateful to the Serveis Centrals d'Instrumentació Científica (SCIC-UJI) for providing with spectroscopic facilities. We would also like to thank the Generalitat Valenciana for a fellowship (S-R.-B.).

Keywords: Rhodium - graphene - catalyst immobilization • catalyst recyclability $\bullet \mathrm{N}$-heterocyclic carbene

\section{References}


[1] a) C. W. Jones, Top. Catal. 2010, 53, 942-952; b) D. J. Cole-Hamilton, Science 2003, 299, 1702-1706; c) Z. Wang, G. Chen and K. L. Ding, Chem. Rev. 2009, 109, 322-359; d) J. A. Gladysz, Chem. Rev. 2002, 102, 32153216; e) J. M. Fraile, J. I. Garcia and J. A. Mayoral, Chem. Rev. 2009, 109, 360-417; f) C. Coperet, M. Chabanas, R. P. Saint-Arroman and J. M. Basset, Angew. Chem. Int. Ed. 2003, 42, 156-181; g) G. C. Bond, Chem. Soc. Rev. 1991, 20, 441-475.

[2] M. R. Axet, O. Dechy-Cabaret, J. Durand, M. Gouygou and P. Serp, Coord. Chem. Rev. 2016, 308, 236-345.

[3] a) L. Rodriguez-Perez, M. Angeles Herranz and N. Martin, Chem. Commun. 2013, 49, 3721-3735; b) V. Georgakilas, M. Otyepka, A. B. Bourlinos, V. Chandra, N. Kim, K. C. Kemp, P. Hobza, R. Zboril and K. S. Kim, Chem. Rev. 2012, 112, 6156-6214.

[4] a) A. Le Goff, B. Reuillard and S. Cosnier, Langmuir 2013, 29, 8736-8742; b) J. A. Mann, J. Rodriguez-Lopez, H. D. Abruna and W. R. Dichtel, J. Am. Chem. Soc. 2011, 133, 17614-17617.

[5] a) M. Keller, V. Colliere, O. Reiser, A. M. Caminade, J. P. Majoral and A. Ouali, Angew. Chem. Int. Ed. 2013, 52, 3626-3629; b) S. Wittmann, A. Schatz, R. N. Grass, W. J. Stark and O. Reiser, Angew. Chem. Int. Ed. 2010, 49, 1867-1870; c) P. Kang, S. H. Zhang, T. J. Meyer and M. Brookhart, Angew. Chem. Int. Ed. 2014, 126, 8853-8857; d) J. D. Blakemore, A. Gupta, J. J. Warren, B. S. Brunschwig and H. B. Gray, J. Am. Chem. Soc. 2013, 135, 18288-18291; e) D. Ventura-Espinosa, A. Marza-Beltran and J. A. Mata, Chem. Eur. J. 2016, 22, 17758-17766; f) D. Ventura-Espinosa, C. Vicent, M. Baya and J. A. Mata, Catalysis Science \& Technology 2016, 6, 8024-8035.

[6] a) R. Zhong, A. C. Lindhorst, F. J. Groche and F. E. Kuhn, Chem. Rev. 2017, 117, 1970-2058; b) K. V. S. Ranganath, S. Onitsuka, A. K. Kumar and J. Inanaga, Catalysis Science \& Technology 2013, 3, 2161-2181; c) W. J. Sommer and M. Weck, Coord. Chem. Rev. 2007, 251, 860-873.

[7] S. Sabater, J. A. Mata and E. Peris, Organometallics 2015, 34, 1186-1190.

[8] S. Sabater, J. A. Mata and E. Peris, ACS Catal. 2014, 4, 2038-2047.

[9] S. Ruiz-Botella and E. Peris, Chem. Eur. J. 2015, 21, 15263-15271.

[10] E. Peris, Chem. Commun. 2016, 52, 5777-5787.

[11] S. Ruiz-Botella and E. Peris, Organometallics 2014, 33, 5509-5516.

[12] a) B. J. Truscott, G. C. Fortman, A. M. Z. Slawin and S. P. Nolan, Org. Bio. Chem. 2011, 9, 7038-7041; b) M. Pucheault, S. Darses and J. P. Genet, Tetrahedron Lett. 2002, 43, 6155-6157; c) M. Pucheault, S. Darses and J. P.
Genet, Eur. J. Org. Chem. 2002, 3552-3557; d) M. Sakai, H. Hayashi and N. Miyaura, Organometallics 1997, 16, 4229-4231; e) T. Hayashi, M. Takahashi, Y. Takaya and M. Ogasawara, J. Am. Chem. Soc. 2002, 124, 5052-5058.

[13] a) I. Penafiel, I. M. Pastor, M. Yus, M. A. Esteruelas and M. Olivan Organometallics 2012, 31, 6154-6161; b) I. Bratko, G. Guisado-Barrios, I. Favier, S. Mallet-Ladeira, E. Teuma, E. Peris and M. Gómez, Eur. J. Org. Chem. 2014, 2160-2167; c) C. Mejuto, B. Royo, G. Guisado-Barrios and E. Peris, Beilstein J. Org. Chem. 2015, 11, 2584-2590; d) C. Mejuto, G. GuisadoBarrios and E. Peris, Organometallics 2014, 33, 3205-3211.

[14] a) M. Iglesias, M. Aliaga-Lavrijsen, P. J. Sanz Miguel, F. J. FernandezAlvarez, J. J. Perez-Torrente and L. A. Oro, Adv. Synth. Catal. 2015, 357, 350-354; b) M. Iglesias, P. J. Sanz Miguel, V. Polo, F. J. Fernandez-Alvarez, J. J. Perez-Torrente and L. A. Oro, Chem. Eur. J. 2013, 19, 17559-17566; c) J. Cervantes, G. Gonzalez-Alatorre, D. Rohack and K. H. Pannell, Appl. Organomet. Chem. 2000, 14, 146-151; d) J. W. Faller and D. G. D'Alliessi, Organometallics 2002, 21, 1743-1746; e) M. Poyatos, E. Mas-Marza, J. A. Mata, M. Sanau and E. Peris, Eur. J. Inorg. Chem. 2003, 1215-1221; f) G. T. S. Andavan, E. B. Bauer, C. S. Letko, T. K. Hollis and F. S. Tham, J. Organomet. Chem. 2005, 690, 5938-5947; g) M. Viciano, E. Mas-Marza, M. Sanau and E. Peris, Organometallics 2006, 25, 3063-3069; h) T. Murai, E. Nagaya, F. Shibahara, T. Maruyama and H. Nakazawa, J. Organomet. Chem. 2015, 794, 76-80; i) V. Diachenko, M. J. Page, M. R. D. Gatus, M. Bhadbhade and B. A. Messerle, Organometallics 2015, 34, 4543-4552.

[15] a) B. Marciniec, K. H. Maciejewski, C. Pietraszuk and P. Pawluc, Hydrosilylation: A Comprehensive Review on Recent Advances, Springer, Berlin, 2008, p; b) M. Isobe, R. Nishizawa, T. Nishikawa and K. Yoza, Tetrahedron Lett. 1999, 40, 6927-6932; c) A. K. Dash, I. Gourevich, J. Q. Wang, J. X. Wang, M. Kapon and M. S. Eisen, Organometallics 2001, 20, 5084-5104; d) K. Itami, K. Mitsudo, A. Nishino and J. Yoshida, J. Org. Chem. 2002, 67, 2645-2652.

[16] C. H. Jun and R. H. Crabtree, J. Organomet. Chem. 1993, 447, 177-187.

[17] a) R. S. Tanke and R. H. Crabtree, J. Am. Chem. Soc. 1990, 112, 79847989; b) I. Ojima, N. Clos, R. J. Donovan and P. Ingallina, Organometallics 1990, 9, 3127-3133.

[18] C. M. Wong, D. B. Walker, A. H. Soeriyadi, J. J. Gooding and B. A. Messerle, Chem. Sci. 2016, 7, 1996-2004. 


\section{Entry for the Table of Contents}

\section{FULL PAPER}

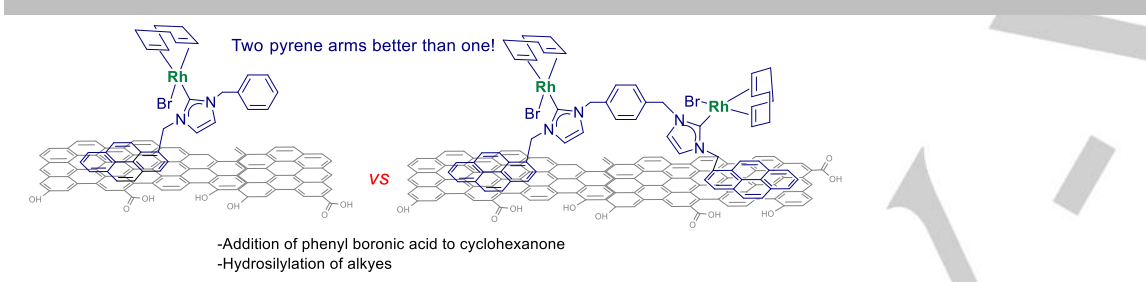

Sheila Ruiz-Botella, Eduardo Peris*

Page No. - Page No.

Title

Two NHC complexes of rhodium (I) adonerd with pyrene functionalities were supported onto the surface of reduced graphene oxide. The dimetallic complex with two pyrene tags, affords higher catalytic activity, better recyclability and improved selectivity compared to the related monometallic complex with only one pyrene functionality. 